\title{
A higher effort-based paradigm in physical activity and exercise for public health: making the case for a greater emphasis on resistance training
}

\author{
James Steele ${ }^{1 *}$ D, James Fisher ${ }^{1}$, Martin Skivington ${ }^{1}$, Chris Dunn ${ }^{1}$, Josh Arnold ${ }^{1}$, Garry Tew ${ }^{2}$, Alan M. Batterham ${ }^{3}$, \\ David Nunan ${ }^{4}$, Jamie M. O'Driscoll ${ }^{5}$, Steven Mann ${ }^{6}$, Chris Beedie, ${ }^{5,6}$, Simon Jobson 7 , Dave Smith ${ }^{8}$, Andrew Vigotsky ${ }^{9}$, \\ Stuart Phillips ${ }^{10}$, Paul Estabrooks ${ }^{11}$ and Richard Winett ${ }^{12}$
}

\begin{abstract}
It is well known that physical activity and exercise is associated with a lower risk of a range of morbidities and all-cause mortality. Further, it appears that risk reductions are greater when physical activity and/or exercise is performed at a higher intensity of effort. Why this may be the case is perhaps explained by the accumulating evidence linking physical fitness and performance outcomes (e.g. cardiorespiratory fitness, strength, and muscle mass) also to morbidity and mortality risk. Current guidelines about the performance of moderate/vigorous physical activity using aerobic exercise modes focuses upon the accumulation of a minimum volume of physical activity and/or exercise, and have thus far produced disappointing outcomes. As such there has been increased interest in the use of higher effort physical activity and exercise as being potentially more efficacious. Though there is currently debate as to the effectiveness of public health prescription based around higher effort physical activity and exercise, most discussion around this has focused upon modes considered to be traditionally 'aerobic' (e.g. running, cycling, rowing, swimming etc.). A mode customarily performed to a relatively high intensity of effort that we believe has been overlooked is resistance training. Current guidelines do include recommendations to engage in 'muscle strengthening activities' though there has been very little emphasis upon these modes in either research or public health effort. As such the purpose of this debate article is to discuss the emerging higher effort paradigm in physical activity and exercise for public health and to make a case for why there should be a greater emphasis placed upon resistance training as a mode in this paradigm shift.
\end{abstract}

Keywords: Physical activity, Exercise, Fitness, Cardiorespiratory, Strength, Muscle, Public health, Morbidity, Mortality

\section{Background}

It is hard to argue against the value of physical activity and/or exercise for health and longevity. Engaging in these behaviors is associated with a reduced risk of allcause mortality [1,2], and a dose-response relationship appears to exist between increasing volume (i.e., amount or duration) of physical activity and exercise engaged in and reduced mortality risk [3-5]. As a result most guidelines regarding physical activity and exercise are based

\footnotetext{
* Correspondence: james.steele@solent.ac.uk

${ }^{1}$ School of Sport, Health, and Social Science, Southampton Solent University,

Southampton SO14 OYN, UK

Full list of author information is available at the end of the article
}

upon the accumulation of a minimum volume (i.e. a combination of $30 \mathrm{~min}$ of moderate intensity $[50-70 \%$ of maximum heart rate (MHR)] five times per week AND/OR $20 \mathrm{~min}$ of vigorous intensity [70-80\% MHR] three times per week).

However, the efficacy of these recommendations could be considered disappointing in view of recent studies showing that only a marginal reduction in morbidity risk factors and all-cause mortality occurs when they are met $[6,7]$. In contrast, the intensity of effort (i.e. relative challenge) of physical activity and exercise may be a more impactful moderator of risk reduction than exercise volume $[8,9]$. Although a combined approach (i.e., 
higher volumes of low effort exercise combined with lower volumes of high effort exercise) may offer the most benefit, in isolation, engaging in higher effort physical activity and exercise would appear most impactful [10]. It is important to note that most evidence for the benefits of physical activity and exercise comes from observational studies and that evidence is mixed amongst randomised controlled trials and systematic reviews [11]. Despite this uncertainty, it is worth considering why the observational evidence seems to support engagement in higher effort exercise as being more efficacious compared with lower effort yet higher volume approaches.

Evidence is accumulating that poor performance in fitness related measures, across the lifespan, may be some of the strongest risk factors for quality of life, function, and increased risk of a range of morbidities, as well as increased all-cause mortality. The now classic work of Blair et al. [12] reported that cardiorespiratory fitness is a stronger predictor of mortality than even smoking. More recent studies support similar relationships between health, longevity, and cardiorespiratory fitness $[6,7,13-19]$, in addition to other characteristics notably modifiable through physical activity and exercise such as muscle mass [20, 21], and strength [22-32]. Considering that these variables (cardiorespiratory fitness, strength and muscle mass) are strong predictors of morbidity and mortality, from the perspective of an exercise physiologist, it might appear unsurprising that higher effort physical activity and exercise also appears to be a strong predictor compared with higher volume, lower effort physical activity and exercise. The use of exercise interventions with high intensity of effort has shown promising efficacy in improving outcomes for a range of cardiometabolic diseases, and may also be superior to moderate intensity of effort programmes at improving outcomes such as cardiorespiratory fitness [33-35]. Indeed, in an experimental examination of the current aerobic physical activity guidelines, Church et al. [36] had groups of participants perform varying volumes of exercise. Participants exercised at an average of $\sim 3.6 \mathrm{METs}$, considered 'moderate' activity. Even in the group exceeding the volume of the current guidelines by $50 \%$ there was minimal to no effect on a range of risk factors for coronary heart disease, including cardiorespiratory fitness [36].

A paradigm shift is beginning with many now discussing exercise prescription for public health based on an effort driven model (i.e., the prescription of exercise at higher or near maximal relative efforts), and thus a wider range of exercise options to increase reach to a broader and more representative portion of the population. This is evident by the fact that the concept is being taken seriously enough to be the subject of debate at international conferences [37], in addition to the increasing number of studies being funded and published examining the applications of higher intensity of effort interventions for an increasing range of conditions. However, most of the focus around this area has been primarily upon what are often colloquially termed 'cardio' exercise modalities (i.e. locomotive based modes such as cycling, running, rowing, incline walking, and stairclimbing). Indeed, though an effort driven model opens up options for exercise, a mode which the authors of this paper believe has been underappreciated and received less discussion in the wider field of physical activity and exercise for public health is resistance training $(\mathrm{RT})$.

\section{Resistance training for public health}

$\mathrm{RT}$ is a modality of exercise that has existed in many forms. As early as 480 BC Greek soldiers engaged in a form of RT, often referred to as calisthenics, using their bodyweight to provide resistance during exercise. The use of calisthenics based RT reached a peak in the early nineteenth century with the various gymnastic schools, most notably the Swedish school of Per Henrick Ling. The notion of applying progression to RT by using increasingly heavier forms of external resistance finds its origins in the myth of Milo of Croton who was said to have carried a bull across his shoulders after having lifted it as a new-born calf every day until its maturity. Free weights, such as barbells and dumbbells, are a type of external resistance with which most are familiar today, and the modern adjustable incarnations of these implements came into popularity through the Milo Barbell company, founded by Alan Calvert in 1902. Machines to provide adjustable external resistance are now also commonplace in most gyms and fitness centres. The first designs for such devices are credited to Gustav Zander in the late nineteenth century, though their resurgence and current popularity find their source in the Nautilus Sport/Medical Industries Company founded by Arthur Jones in the 1970s. Many varied forms of RT exist nowadays, the list above not being exhaustive, yet there are some key defining characteristics of how RT is commonly recommended and applied that characterise and differentiate it from other exercise modes. These include repeated or sustained muscular actions against some form of resistance, at a relatively high effort, for a relatively brief duration, and relatively infrequently. Notably RT improves both strength and muscle mass with effort being a primary determinant of these outcomes [38, 39]. Moreover, RT may also improve cardiorespiratory fitness, particularly if performed to a high enough intensity of effort [40].

Evidence has accumulated that suggests that engaging in some form of muscle strengthening activity, such as RT, has an impact on a range of health and morbidity related risk factors [41-45], multi-morbidity risk [46, 47], 
and all-cause mortality [48-50], across both healthy and clinical populations. However, a question remains as to how important a place RT should have in current physical activity and exercise guidelines for public health. Within the academic literature numerous authors have argued that RT should have a more prominent place within guidelines [51-53]. In fact, most current activity guidelines around the world already include recommendations to engage in some form of muscle strengthening activity at least twice per week [54-58]. Despite this, as Strain et al. [59] noted recently, these are more often than not the 'forgotten' portion of the guidelines. However, in addition to the lack of focus in public health policy, we have further concerns with the current state of these recommendations, particularly from the perspective of RT as a higher effort mode of exercise. Recommendations for what constitutes a muscle strengthening activity, considering the potential importance of high effort in moderating efficacy, could be considered as insufficient except in the most unfit of persons. For example, the UK National Health Service recommends the following: lifting weights, working with resistance bands, doing exercises that use your own bodyweight, such as pushups and sit-ups, heavy gardening such as digging and shovelling, and yoga. The first three of these examples would likely be considered to meet our conceptualisation of RT as a relatively high effort activity. Nevertheless, the inclusion of low resistance, and thus possibly lower effort activities, such as gardening and yoga, could be considered questionable. Though Ekblom-Bak et al. [60] have reported that non-exercise physical activities (NEPA) such as gardening, home/car maintenance, and housework may contribute to improved health and longevity independent of other directed exercise, their examination of NEPA was based on frequency of participation and included a range of activities that might vary in both volume and intensity of effort. Others have reported that many, and in particular women, consider domestic activities to contribute to their moderate to vigorous physical activity, yet such activities are negatively associated with body composition, suggesting they may be insufficient in providing the benefits normally associated with physical activity and exercise [61]. Considering yoga, though participation may be efficacious in older adults [62, 63], possibly due to it requiring a greater relative intensity of effort in this population, a recent study found that after adjusting for age, yoga participation was not associated with a reduced all-cause mortality risk [64]. Again, this might be attributed to yoga presenting an insufficient stimulus with regards to effort in many populations. In fact, studies which have compared groups completing RT based interventions to control groups performing a range of low effort exercises, including yoga, report significant improvements in most health and fitness related outcomes for RT, yet little to no change in controls $[65,66]$. Further, these studies were in disabled, older, female cardiac patients where activities such as yoga might be considered to present a relatively greater effort than in most persons.

Merely 'going through the motions' by participating in some of the suggested muscle strengthening activities may not produce the desired outcomes. Yet outcomes are what matter to stakeholders, including public health commissioners and policy makers [37, 67]. A recent study comparing the behaviour (i.e. meeting the muscle strengthening activity guidelines), to the outcome of that behaviour (i.e., strength), upon all-cause mortality supports just that. Dankel and colleagues [68] found that those meeting the guidelines but who were not in the top quartile for strength did not have a significant reduction in all-cause mortality risk. Those who were in the top quartile for strength but did not meet the guidelines (i.e., persons that could be considered 'naturally strong') had a $\sim 46 \%$ risk reduction. But, more tellingly, those who met the guidelines and were in the top quartile for strength had $\mathrm{a} \sim 72 \%$ risk reduction. Though observational in nature, this last group could be considered as those most likely to already be engaged in efficacious muscle strengthening activities e.g. RT. Evidently it is imperative that clear instructions regarding the application of appropriate effort during RT activities are implemented into public health guidelines. The most recent Canadian guidelines [56] make a greater attempt at specifically recommending participation in RT (resistance machines, free weights, cable pulleys, bands, etc.) without offering suggestions of activities that may lack efficacy.

Why there is such a lack of emphasis upon RT within current public health guidelines may stem from a number of factors. It appears likely that some element of mischaracterisation of what constitutes RT may be influential, as would appear evident by the currently recommended examples of muscle strengthening activities. As a result, there is seemingly lacklustre support for an approach emphasising RT. Indeed the most recent report informing the current UK guidelines noted that:

"... any statements on the health benefits of strength training and flexibility should be positioned as secondary and less important than the primary message to adults of undertaking at least $150 \mathrm{~min}$ of aerobic activity per week. "([69], pg, 24).

With policy makers claiming that it has little importance, it is unsurprising that participation in RT receives little emphasis. Indeed, albeit anecdotal, it is our experience that, even at sport and exercise medicine conferences where the value of $\mathrm{RT}$ for public health has been 
discussed, many are not even aware that the current guidelines include recommendations for muscle strengthening activity at all. This lack of emphasis may be a factor responsible for the considerably lower proportion of people engaged in RT compared with those meeting the lower effort aerobic physical activity guidelines. Participation in any form of physical activity or exercise is disappointingly low. Statistics for people meeting the aerobic portion of the guidelines vary from $~ 15-20 \%$ [70-74], though Scotland stands out with particularly high proportions of the population ( $71 \%$ of men and $58 \%$ of women) meeting guidelines [75]. Indeed, a recent study shows that $31 \%$ of men and $24 \%$ of women in Scotland also currently meet the muscle strengthening guidelines [59], with similar rates in England of 34 and 24\% for men and women respectively [76]. However, the activities included as counting towards 'muscle strengthening activity' in the surveillance methods used vary widely. For example, in the latest Scottish survey, 'Workout at Gym' or 'Exercises' might be considered as most closely reflecting participation in RT as described above. But what these categories constituted was not specified and the former was used to specify both 'Weight Training' and 'Exercise Bike' participation. In contrast, surveys specifying 'Weightlifting' in England report rates as low as 5\% for men and 0.9\% for women [70]. Though some data evidently suggests that a similar proportion of people meet the aerobic and muscle strengthening activity guidelines, where differences exist these may be due to different surveillance methods used. Indeed, where surveys have more clearly differentiated between these and more specific RT, participation rates are $\sim 5-6 \%[70,73]$. This is cause for concern, as many may believe that they are already engaging in behaviours constituting efficacious muscle strengthening activities when, in fact, they likely are not.

It should be acknowledged that the lack of emphasis in public health policy is not the only potential culprit for the lack of engagement with RT [77]. As with any physical activity and exercise, there are common barriers to participation and RT might be considered to present its own unique ones. In addition to the commonly cited barrier of time to exercise participation, many also report barriers associated with the accessibility to specialised equipment and/or facilities, such as travel time and costs [78-81]. Barriers to participation are also likely to be population specific. Indeed, in older community dwelling adults, a population for whom RT may be of particular benefit, who cite similar access barriers to those noted above, many cite ongoing pain and injury as primary barriers to participation in RT [82].

The suggestion is that many assume participation in exercise or physical activity requires the use of specialised equipment and/or facilities, in addition to extensive time commitments. Indeed, as noted, though it can be performed without equipment (i.e., bodyweight), RT is commonly performed using some kind of equipment to provide resistance (i.e., free weights, resistance machines, elastic resistance bands, etc.) and organizational recommendations regarding RT prescription often emphasise these approaches [83]. The recommendations provided by these organizations are also often complex, timeconsuming, and require heavy loads for resistance. Complexity in their recommendations includes the use of periodisation in addition to the performance of a high volume of exercises performed in multiple sets resulting in a substantial time commitment. However, many of these recommended RT practices have in fact been heavily questioned. Periodisation is lacking in evidence for its efficacy $[84,85]$, multi-jont exercises appear to offer similar benefits as single joint-exercises for most muscle groups [86], and assuming effort is sufficiently high singleset protocols offer largely similar benefits to multiple-set protocols $[38,39]$. Indeed a number of studies provide examples of where a relatively low to moderate dose of RT has been effective for a range of health outcomes for both young and old populations (e.g. [87-95]). Further, many oragnisations also imply in their recommendations of particular relative loads (i.e., \% of 1 repetition maximum $[\mathrm{RM}])$ that a readily modifiable external resistance is in fact necessary, which may not be the case [96, 97], with perhaps the exception of for outcomes such as bone mineral density where, though low loads can still produce benefit, higher loads might optmise these outcomes [98]. As such, many are likely unaware that RT can be performed in a time efficient manner in a variety of settings with minimal/no equipment. For example, in Mexican primary care settings it is common to have exercise space and water bottles of various sizes filled with sand for RT activities-materials that are locally available at little or no cost, but can be used in a facility or home environment.

On top of this, despite recent work looking to understand barriers and motivators to participation in RT [82], a theoretical model to guide interventions to increase initiation and adherence is currently lacking [77]. Thus we are currently in a position whereby we have considerable evidence supporting the efficacy of RT (i.e., that it works when people do it under ideal conditions), but a considerable lack of evidence examining its effectiveness (i.e., whether people will actually do it under ecologically valid conditions). At present this is a conundrum for most of sport and exercise medicine [67], though, with its lack of emphasis in public health research, even more so for RT.

\section{Conclusions}

We acknowledge that for many the primary issue relating to physical activity and public health is first and foremost how we can get people to do any in the first place. 
In this respect there are contrasting opinions and ongoing debate regarding the application of higher effort models of physical activity and exercise to public health [37]. It might therefore seem almost self-indulgent for researchers to opine on the potential benefits of RT in this respect. However, though at present there may be little evidence supporting the effectiveness of ecologically valid approaches to RT for public health, we are quite convinced that at present we have considerable evidence suggesting it may be an efficacious approach. As such, our motivation for penning the present piece is twofold.

First we hope to increase interest in RT such that more care providers might participate in specific conversations about its engagement and participation. Indeed, it has recently been argued that doctors should be able to prescribe exercise like a drug [99] and an effort based model to inform RT prescription would appear to have considerable merits [52]. Few doctors make recommendations for physical activity participation of any kind and in instances when they do they invariably emphasise aerobic exercise (59\% of the time) compared with RT $(13 \%$ of the time) [100]. Further, when systematic approaches to address exercise promotion in clinical settings are developed, screening and exercise promotion messages often do not address RT leaving physicians and patients without basic tools to cue a conversation and goal setting in the area $[101,102]$. The power of such conversations to at least heighten awareness of RT as a complementary or even alternative approach, in physical activity and exercise should not be overlooked. The elderly in particular seem receptive to physician's recommendations in this regard, with this being almost as commonly cited as a motivator for RT participation as knowledge of its health benefits [82].

Appreciably, the above intent is unlikely to translate to a sudden upsurge in public participation in efficacious RT approaches. Nonetheless, our second motivation is that that this piece may serve to stimulate a wider academic interest in RT from a public health perspective, and to highlight the need for trials examining not only the efficacy of this mode, but also the effectiveness. Rigorous trials examining complex interventions - informed by appropriate theoretical models aimed at behavioural change to overcome barriers, increase initiation, and maintain adherence to RT interventions - are essential, in combination with appropriate health outcomes examined as dependent variables (outcomes), as such variables are important to stakeholders and policy makers. In addition to this is a need to identify interventions that are cost effective and sustainable in their implementation. There has been a call for all exercise trials, including RT, to be examined in real world settings such as community centres [103].
Some models already exist for better integrating efficacious RT into public health interventions, including the Lift for Life ${ }^{\bullet}$ RT program in Australia. Recent work has examined the factors associated with engaging in RT behaviours in addition to the application of theory-based approaches for maintaining RT behaviours [82, 104-106], and evaluations of community based interventions are emerging [107]. Thus far, findings have been promising, as they suggest that there are likely simple, low cost, effective approaches possible to increase RT behaviours. We are optimistic that this piece and further work may help to finally push the present higher effort paradigm shift to more explicitly and prominently include RT in its message for the benefit of public health.

\section{Abbreviations}

MHR: Maximum heart rate; NEPA: Non-exercise physical activities; RM: Repetition maximum; RT: Resistance training

\section{Acknowledgements}

Not applicable.

Funding

Not applicable.

Availability of data and materials

Not applicable.

\section{Author's contributions}

IS conceived the idea for the manuscript and produced the first draft. All authors were involved in critical review and rewriting of subsequent drafts. All authors read and approved the final manuscript.

\section{Competing interests}

The authors declare they have no competing interests.

Consent for publication

Not applicable.

Ethics approval and consent to participate Not applicable.

\section{Publisher's note}

Springer Nature remains neutral with regard to jurisdictional claims in published maps and institutional affiliations.

\section{Author details}

${ }^{1}$ School of Sport, Health, and Social Science, Southampton Solent University, Southampton SO14 OYN, UK. ${ }^{2}$ Exercise and Health Sciences Department: Sport, Exercise and Rehabilitation, Northumbria University, Newcastle NE1 8ST, UK. ${ }^{3}$ School of Health and Social Care, Teesside University, Middleborough TS1 3BA, UK. ${ }^{4}$ Centre for Evidence-Based Medicine, Nuffield Department of Primary |Care Health Sciences, University of Oxford, Oxford OX2 6GG, UK. ${ }^{5}$ School of Human and Life Sciences, Canterbury Christ Church University, Kent CT1 1QU, UK. ${ }^{6}$ UK Active Research Institute, UK Active, London WC1R 4HE, UK. ${ }^{7}$ Department of Sport \& Exercise, University of Winchester, Winchester SO22 4NR, UK. ${ }^{8}$ Department of Exercise and Sport Science, Manchester Metropolitan University, Crewe CW1 5DU, UK.

${ }^{9}$ Department of Biomedical Engineering, Northwestern University, Evanston, IL, USA. ${ }^{10}$ Department of Kinesiology, McMaster University, Hamilton, ON,

Canada. ${ }^{11}$ College of Public Health, University of Nebraska Medical Centre, Omaha, NE, USA. ${ }^{12}$ Psychology Department, Virginia Tech, Blacksburg, VA, USA. 


\section{Received: 26 November 2016 Accepted: 31 March 2017} Published online: 05 April 2017

\section{References}

1. Paffenbarger RS, Hyde RT, Wing AL, Hsieh CC. Physical activity, all-cause mortality, and longevity of college alumni. N Engl J Med. 1986;314:605-13.

2. Nocon M, Hiemann T, Muller-Riemenschneider F, Thalau F, Roll S, Willich SN Association of physical activity with all-cause and cardiovascular mortality: a systematic review and meta-analysis. Eur J Cardiovasc Prev Rehabil. 2008;15: 239-46

3. Lee I, Skerrett PJ. Physical activity and all-cause mortality: what is the doseresponse relation? Med Sci Sports Exerc. 2001;33:S459-71.

4. Byberg L, Melhus H, Gedeborg R, Sundstrom J, Ahlbom A, Zethelius B, Berglund LG, Wolk A, Michaelsson K. Total mortality after changes in leisure time physical activity in 50 year old men: 35 year follow-up of population based cohort. BMJ. 2009;338:b688.

5. Loprinzi P. Dose-response association of moderate-to-vigorous physical activity with cardiovascular biomarkers and all-cause mortality: considerations by individual sports, exercise and recreational physical activities. Prev Med. 2015:81:73-7.

6. Lee DC, Sui X, Ortega FB, Kim YS, Church TS, Winett RA, Ekelund U, Katzmarzyk PT, Blair SN. Comparisons of leisure-time physical activity and cardiorespiratory fitness as predictors of all-cause mortality in men and women. Br J Sports Med. 2011;45:504-10.

7. Wen CP, Wai JP, Tsai MK, Yang YC, Cheng TY, Lee MC, Chan HT, Tsao CK, Tsai SP, Wu X. Minimum amount of physical activity for reduced mortality and extended life expectancy: a prospective cohort study. Lancet. 2011;378:1244-53.

8. Lee I, Sesso HD, Oguma Y, Paffenbarger RS. Relative intensity of physical activity and risk of coronary heart disease. Circulation. 2003;107:1110-6.

9. Wisloff U, Nilsen TI, Droyvold WB, Morkved S, Slordahl SA, Vatten L. A single weekly bout of exercise may reduce cardiovascular mortality: how little pain for cardiac gain? 'The HUNT study, Norway'. Eur J Cardiovasc Prev Rehabil. 2006;13:798-804

10. Loprinzi PD, Davies RE. Effects of individual, combined, and isolated physical activity behaviors on all-cause mortality and CVD-specific mortality: prospective cohort study among U.S. adults. Physiol Behav. 2015;151:355-9.

11. Nunan D, Mahtani KR, Roberts N, Heneghan C. Physical activity for the prevention and treatment of major chronic disease: an overview of systematic reviews. Syst Rev. 2013;2:56.

12. Blair SN, Kampert JB, Kohl HW, Barlow CE, Macera CA, Paffenbarger RS, Gibbons LW. Influences of cardiorespiratory fitness and other precursors on cardiovascular disease and all-cause mortality in men and women. JAMA. 1996:276:205-10

13. Kokkinos P, Myers J, Kokkinos JP, Pittaras A, Narayan P, Manolis A, Karasik P, Greenberg M, Papademetriou V, Singh S. Exercise capacity and mortality in balck and white men. Circulation. 2008;117:614-22.

14. Laukkanen JA, Pukkala E, Rauramaa R, Makikallio TH, Toriola AT, Kurl S. Cardiorespiratory fitness, lifestyle factors and cancer risk and mortality in Finnish men. Eur J Cancer. 2010:46:355-63.

15. Ortega FB, Lee D, Katmarzyk PT, Ruiz JR, Sui X, Church TS, Blair SN. The intriguing metabolically healthy but obese phenotype: cardiovascular prognosis and role of fitness. Eur Heart J. 2012;34(5):389-97.

16. Ruderman N, Chisholm D, Pi-Sunyer X, Schneider S. The metabolically obese, normal-weight individual revisited. Diabetes. 1998:47:699-713.

17. Loprinzi PD. Cardiorespiratory capacity and leukocyte telomere length among adults in the United States. Am J Epidemiol. 2015;182:198-201.

18. Kokkinos P, Myers J, Faselis C, Panagiotakos DB, Doumas M, Pittaras A, Manolis A, Kokkinos JP, Karasik P, Greenberg M, Papademetriou V, Fletcher R. Exercise capacity and mortality in older men: a 20-year follow-up study. Circulation. 2010:122:790-7.

19. Kodama S, Saito K, Tanaka S, Maki M, Yachi Y, Asumi M, Sugawara A, Totsuka K, Shimano H, Ohashi Y, Yamada N, Sone H. Cardiorespiratory fitness as a quantitative predictor of all-cause mortality and cardiovascular events in health men and women: a meta-analysis. JAMA. 2009;301:2024-35

20. Srikanthan $\mathrm{P}$, Karlamangla AS. Muscle mass index as a predictor of longevity in older adults. Am J Med. 2014;127:547-53.

21. Sriknathan $\mathrm{P}$, Horwich $\mathrm{TB}$, Tseng $\mathrm{CH}$. Relation of muscle mass and fat mass to cardiovascular disease mortality. Am J Cardiol. 2016;117:1355-60.
22. Newman AB, Kupelian V, Visser M, Simonsick EM, Goodpaster BH, Kritchevsky SB, Tylavsky FA, Rubin SM, Harris TB. Strength, but not muscle mass, is associated with mortality in the health, aging and body composition study cohort. J Gerontol A BiolSci Med Sci. 2006;61:72-7.

23. Ruiz JR, Sui X, Lobelo F, Morrow JR, Jackson JW, Sjostrom M, Blair SN. Association between muscular strength and mortality in men: prospective cohort study. BMJ. 2008;337:439.

24. Buckner SL, Loenneke JP, Loprinzi PD. Lower extremity strength, systemic inflammation and all-cause mortality: application to the "fat but fit" paradigm using cross-sectional and longitudinal designs. Physiol Behav. 2015:149:199-202.

25. Leong DP, Teo KK, Rangarajan S, Lopez-Jaramillo P, Avezum A Jr, Orlandin A, Seron P, Ahmed SH, Rosengren A, Kelishadi R, Rahman O, Swaminathan S, Igbal R, Gupta R, Lear SA, Oquz A, Yusoff K, Zatonska K, Chifamba J, lqumbor E, Mohan V, Gu H, Li W, Yusuf S. Prospective Urban Rural Epidemiology (PURE) Study Investigators. Prognostic value of grip strength: findings from the prospective urban rural epidemiology (PURE) study. Lancet. 2015;386:266-73.

26. Loprinzi PD. Lower extremity muscular strength, sedentary behaviour, and mortality. Age. 2016;38:32.

27. Lopez P, Radaelli R, Rech A, Wilhelm EN, Pinto RS. Muscle quality, but not muscle thickness is decreased in different age groups of active older women. RevistaBrasileira de Cineantropometria e DesempenhoHumano. $2015 \cdot 17 \cdot 347-56$

28. Gaudaupe-Grau A, Carnicero JA, Gomez-Cabello A, Gutierrez Avila G, Humanes S, Alegre LM, Castro M, Rodriguez-Manas L, Garcia-Garcia FJ. Association of regional muscle strength with mortality and hopsitalisation in older people. Age Ageing. 2015;44:790-5.

29. Strand BH, Cooper R, Bergland A, Jorgensen L, Schirmer H, Skirbekk V, Emaus $\mathrm{N}$. The association of grip strength fro midlife onwards with all-cause and cause-specific mortality over 17 years of follow-up in the Tromso study. J Epidemiol Community Health. 2016; Epub ahead of print

30. Ortega FB, Silventoinen K, Tynelius P, Rasmussen F. Muscular strength in male adolescents and premature death: cohort study of one million participants. BMJ. 2012;345:e7279.

31. Kamiya K, Masuda T, Tanaka S, Hamazaki N, Matsue Y, Mezzani A, Matsuzawa R, Nozaki K, Maekawa E, Noda C, Yamaoka-Tojo M, Arai Y, Matsunaga A, Izumi T, Ako J. Quadriceps strength as a predictor of mortality in coronary artery disease. Am J Med. 2015;128:1212-9.

32. Loprinzi PD, Loenneke JP. Lower extremity muscular strength and leukocyte telomere length: implications of muscular strength in attenuating agerelated chronic disease. J Phys Act Health. 2016;13:454-7.

33. Gibala MJ, Little JP, MacDonald MJ, Hawley J. Physiological adaptations to low-volume, high intensity interval training in health and disease. J Physiol. 2012:590:1077-84

34. Tabata I, Nishimura K, Kouzaki M, Hirai Y, Ogita F, Miyachi M, Yamamoto K. Effects of moderate-intensity endurance and high-intensity intermittent training on anaerobic capacity and VO2max. Med Sci Sports Exerc. 1996;28:1327-30.

35. Matsuo T, Saotome K, Seino S, Shimojo N, Matsushita A, lemitsu M, Ohshima $\mathrm{H}$, Tanaka K, Mukai C. Effects of a low-volume aerobic-type interval exercise on VO2max and cardiac mass. Med Sci Sports Exerc. 2014:46:42-50.

36. Church TS, Earnest CP, Skinner JS, et al. Effects of difference doses of physical activity on cardiorespiratory fitness among sedentary, overweight or obese postmenopausal women with elevated blood pressure. JAMA. 2007;297:2081-91.

37. Biddle SJH, Batterham AM. High-intensity interval exercise training for public health: a big HIT or shall we HIT it on the head? Int J Behav Nutr Phys Act. 2015;12:95

38. Fisher J, Steele J, Smith D. Evidence-based resistance training recommendations for muscular hypertrophy. Med Sportiva. 2013;17:217-35.

39. Fisher J, Steele J, Smith J, Bruce-Low S. Evidence based resistance training recommendations. Med Sportiva. 2011;15:147-62.

40. Steele J, Fisher J, McGuff D, Bruce-Low S, Smith D. Resistance training to momentary muscular failure improves cardiovascular fitness in humans: a review of acute physiological responses and chronic physiological adaptations. J Exerc Physiol. 2012;15:53-80.

41. Loprinzi PD, Loenneke JP. Engagement in muscular strengthening activities is associated with better sleep. Prev Med Rep. 2015;2:927-9.

42. Clark JE. Diet, exercise or diet with exercise: comparing the effectiveness of treatment options for weight-loss and changes in fitness for adults (18-65 years old) who are overfat, or obese; systematic review and meta-analysis. J Diabetes Metab Disord. 2015;14:31. 
43. Buckner SL, Loenneke JP, Loprinzi PD. Single and combined associations of accelerometer-assessed physical activity and muscle strengthening activities on plasma homocysteine in a national sample. Clin Physiol Funct Imaging 2016; Epub ahead of print

44. Loprinzi PD, Loenneke JP, Abe T. The association between muscle strengthening activities and red blood cell distribution width among a national sample of U.S. adults. Prev Med. 2015;73:130-2.

45. Drenowatz C, Sui X, Fritz S, Lavie CJ, Beattie PF, Church TS, Blair SN. The association between resistance training and cardiovascular disease risk in women. J Sci Med Sport. 2015;18:632-6.

46. Dankel S, Loenneke JP, Loprinzi PD. Participation in muscle strengthening activities as an alternative method for the prevention of multimorbidity. Prev Med. 2015:81:54-7.

47. Dankel S, Loenneke JP, Loprinzi PD. Combined associations of musclestrengthening activities and accelerometer-assessed physical activity on multimorbidity: findings from NHANES. Am J Health Promot. 2016; Epub ahead of print

48. Loprinzi PD. Muscle strengthening activities and mortality with considerations by hearing sensitivity. Int J Audiol. 2016;55(5):320-2.

49. Loprinzi PD, Sng E, Walker JF. Muscle strengthening activity associates with reduced all-cause mortality in COPD. Chronic IIIn 2016; Epub ahead of print

50. Kraschenewski JL, Sciamanna CN, Poger JM, Rovniak LS, Lehman EB, Cooper $A B$, Ballentine $\mathrm{NH}$, Ciccolo JT. Is strength training associated with mortality benefits? A 15 year cohort study of US adults. Prev Med. 2016;87:121-7.

51. Winett RA, Carpinelli RN. Potential health-related benefits of resistance training. Prev Med. 2001;33:503-13.

52. Phillips SM, Winett RA. Uncomplicated resistance training and health-related outcomes: evidence for a public health mandate. Curr Sports Med Rep. 2010;9:208-13.

53. Westcott WL. Resistance training is medicine: effects of strength training on health. Curr Sports Med Rep. 2012;11:209-16.

54. U.S. Department of Health and Human Services. 2008 physical activity guidelines for Americans. 2008; https://health.gov/paguidelines/pdf/ paguide.pdf.

55. UK Department of Health. Physical activity guidelines for adults (19-64 years). 2011; https://www.gov.uk/government/uploads/system/uploads/ attachment_data/file/213740/dh_128145.pdf.

56. Canadian Society for Exercise Physiology. Canadian physical activity guidelines. 2011; http://www.csep.ca/CMFiles/Guidelines/specialpops/CSEP_ MS PAGuidelines_adults en.pdf.

57. Australian Government Department of Health. Australia's physical activity and sedentary behaviour guidelines. 2014; http://www.health.gov.au/ internet/main/publishing.nsf/content/F01F92328EDADA5BCA257 BF0001E720D/\$File/brochure\%20PA\%20Guidelines_A5_18-64yrs.PDF.

58. World Health Organisation. Information sheet: global recommendations on physical activity for health 18-64 years old. 2011; http://www.who.int/ dietphysicalactivity/publications/recommendations18_64yearsold/en/.

59. Strain T, Fitzsimons C, Kelly P, Mutrie N. The forgotten guidelines: cross-sectional analysis of participation in muscle strengthening and balance \& co-ordination activities by adults and older adults in Scotland. BMC Public Health. 2016;16:1108.

60. Ekblom-Bak E, Ekblom B, Vikstrom M, deFaire U, Hellenius M. The importance of non-exercise physical activity for cardiovascular health and longevity. Br J Sports Med. 2014;48:233-8.

61. Murphy MH, Donnelly P, Breslin G, Shibli S, Nevill AM. Does doing housework keep you healthy? The contribution of domestic physical activity to meeting current recommendations for health. BMC Public Health. 2013;13:966.

62. Patel NK, Newstead AH, Ferer RL. The effects of yoga on physical functioning and health related quality of life in older adults: a systematic review and meta-analysis. J Altern Complement Med. 2012;18:902-17.

63. Youkhana S, Dean CM, Wolff M, Sherrington C, Tiedemann A. Yoga-base exercise improves balance and mobility in people aged 60 and over: a systematic review and meta-analysis. Age Ageing. 2016;45:21-9.

64. Loprinzi PD. Yoga participation and all-cause mortality: national prospective cohort study. Complement Ther Med. 2015;23:757-8.

65. Ades PA, Savage P, Cress ME, Brochu M, Lee NM, Poehlman ET. Resistance training on physical performance in disabled older female cardiac patients. Med Sci Sports Exerc. 2003:35:1265-70.

66. Brochu M, Savage P, Lee M, Dee J, Cress ME, Poehlman ET, Tischler M, Ades PA. Effects of resistance training on physical function in older disabled women with coronary heart disease. J Appl Physiol. 2002;92:672-8.
67. Beedie C, Mann S, Jimenez A, Kennedy L, Lane AM, Domone S, Wilson S, Whyte $G$. Death by effectiveness: exercise as medicine caught in the efficacy trap! Br J Sports Med. 2016;50:323-4.

68. Dankel SJ, Loenneke JP, Loprinzi PD. Determining the importance of meeting muscle-strengthening activity guidelines: is the behaviour or the outcome of the behaviour (strength) a more important determinant of allcause mortality? Mayo Clin Proc. 2015;91:166-74.

69. Bull F, Biddle S, Buchner D, Ferguson R, Foster C, Fox K, Haskell B, Mutrie M, Reilly J, Riddoch C, Skelton D, Stratton G, Tremblay M, Watts C. Physical activity guidelines in the UK: review an recommendations. 2010; https:// www.gov.uk/government/uploads/system/uploads/attachment_data/file/ 213743/dh_128255.pdf.

70. Department for Culture, Media and Sport, Jones H, Millward P, Buraimo B. Adult participation in sport: analysis of the taking part survey. 2011; https:// www.gov.uk/government/uploads/system/uploads/attachment_data/file/ 137986/tp-adult-participation-sport-analysis.pdf.

71. Centre for Disease Control and Prevention. Trends in strength trainingUnited States 1998-2004. p. 2006. http://www.cdc.gov/mmwr/preview/ mmwrhtml/mm5528a1.htm.

72. Centre for Disease Control and Prevention. Early release of selected estimates based on data from the National Health Interview Survey, January-September 2014. p. 2015. http://www.cdc.gov/nchs/data/nhis/ earlyrelease/earlyrelease201503_07.pdf.

73. Loustalot F, Carlson SA, Kruger J, Buchner DM, Fulton JE. Muscle strengthening activities and participation among adults in the United States. Res Q Exerc Sport. 2013;84:30-8.

74. Dalbo VJ, Czerepusko JB, Tucker PS, Kingsley MI, Moon JR, Young K, Scanlan AT. Not sending the message: a low prevalence of strength-based exercise participation in rural and regional Central Queensland. Aust J Rural Health. 2015;23:295-301.

75. Strain T, Fitzsimons C, Foster C, Mutrie N. Age-related comparisons by sex in the domains of aerobic physical activity for adults in Scotland. Prev Med Rep. 2016;3:90-7.

76. Scholes S, Mindell J. Chapter 2: physical activity in adults. In: Craig R, Mindell J, editors. Health survey for England 2012 volume 1: health, social care and lifestyles. Leeds: Health and Social Care Information Centre; 2013.

77. Winett RA, Williams DM, Davy BM. Initiating and maintaining resistance training in older adults: a social cognitive theory-based approach. $\mathrm{Br}$ J Sports Med. 2009;43:114-9.

78. McCormack G, Giles-Corti B, Lange A, Smith T, Martin K, Pikora TJ. An update of recent evidence of the relationship between objective and selfreport measures of the physical environment and physical activity behaviours. J Sci Med Sport. 2004;7:81-92.

79. Daskapan A, Tuzun EH, Eker L. Perceived barriers to physical activity in university students. J Sports Sci Med. 2006;5:615-20.

80. Gomez-Lopez M, Gallegos AG, Extermera AB. Perceived barriers by university students in the practice of physical activities. J Sports Sci Med. 2010;9:374-81.

81. Trost SG, Owen N, Bauman AE, Sallis JF, Brown W. Correlates of adults' participate on in physical activity: review and update. Med Sci Sports Exerc. 2002;34:1996-2001.

82. Burton $E$, Lewin $G$, Pettigrew $S$, Hill A, Bainbridge L, Farrier $K$, Langdon T, Airey $P$, Hill KD. Identifying motivators and barriers to older communitydwelling people participating in resistance training: a cross-sectional study. J Sports Sci. 2016; Epub ahead of print

83. Ratamess NA, Alvar BA, Evotoch TK, Housh TJ, Kibler WB, Kraemer WJ, Triplett NT. American College of Sports Medicine position stand. Progression models in resistance training for healthy adults. Med Sci Sports Exerc. 2009:41:687-708.

84. Mattocks KT, Dankel SJ, Buckner SL, Jessee MB, Counts BR, Mouser JG, Laurentino GC, Loenneke JP. Periodization: what is it good for? J Trainol. 2016;5:6-12

85. Conlon JA, Newton RU, Tufano JJ, Banyard HG, Hopper AJ, Ridge AJ, Haff GG. Periodization strategies in older adults: impact on physical function and health. Med Sci Sports Exerc. 2016;48:2426-36.

86. Gentil P, Fisher J, Steele J. A review of the acute effects and long-term adaptation of single-joint and multi-joint exercise during resistance training. Sports Med 2016; Epub ahead of print

87. Koffler K, Menkes A, Redmond A, Whitehead WE, Pratley RE, Hurley BF. Strength training accelerates gastrointestinal transit $\mathrm{n}$ middle-aged and older men. Med Sci Sports Exerc. 1992;24:415-9. 
88. Brooks N, Lyne JE, Gordon PL, Roubenoff R, Nelson ME, Castaneda-Sceppa C. Strength training improves muscle quality and insulin sensitivity in Hispanic older adults with type 2 diabetes. Int J Med Sci. 2007;4:19-27.

89. Campbell W, Crim M, Young C, Evans WJ. Increased energy requirements and changes in body composition with resistance training in older adults. Am J Clin Nutr. 1994;60:167-75.

90. Huovinen V, Ivaska KK, Kiviranta R, Bucci M, Lipponen H, Sandboge S, Raiko J, Eriksson JG, Parkkola R, lozzo P, Nuutila P. Bone mineral density is increased after a 16-week resistance training intervention in elderly women with decreased muscle strength. Eur J Endocrinol. 2016;175:571-82.

91. Serra R, Saavedra F, Freitas de Salles B, Dias MR, Costa PB, Alves H, Simão R. The effects of resistance training frequency on strength gains. J Exerc Physiol. 2015;18:37-45.

92. Raj IS, Bird SR, Westfold BA, Shield AJ. Effects of eccentrically biased versus conventional weight training in older adults. Med Sci Sports Exerc. 2012;44:1167-76.

93. Borst SE, De Hoyos DV, Garzarella L, Vincent K, Pollock BH, Lowenthal DT, Pollock ML. Effects of resistance training on insulin-like growth factor-I and IGF binding proteins. Med Sci Sports Exerc. 2001;33:648-53.

94. Abe T, Kojima K, Kearns CF, Yohena H, Fukuda J. Whole body muscle hypertrophy from resistance training: distribution and total mass. Br J Sports Med. 2003:37:543-5.

95. Westcott WL, Winett RA, Annesi JJ, Wojcik JR, AndersonES MPJ. Prescribing physical activity: applying the ACSM protocols for exercise type, intensity, and duration across 3 training frequencies. Phys Sportsmed. 2009;37:51-8.

96. Maeo S, Yoshitake Y, Takai Y, Fukunaga T, Kanehisa H. Neuromuscular adaptations following 12-week maximal voluntary co-contraction training. Eur J Appl Physiol. 2014;114:663-73.

97. Counts BR, Buckner SL, Dankel SJ, Jessee MB, Mattocks KT, Mouser JG, Laurentino GC, Loenneke JP. The acute and chronic effects of "NO LOAD" resistance training. Physiol Behav. 2016;164:345-52.

98. Vincent KR, Braith RW. Resistance exercise and the bone turnover in elderly men and women. Med Sci Sports Exerci. 2002;34:17-23.

99. Nunan D. Doctors should be able to prescribe exercise like a drug. BMJ. 2016;353:i2468.

100. Short CE, Hayman M, Rebar AL, Gunn KM, De Cocker K, Duncan MJ, Turnbull D, Dollman J, van Uffelen JG, Vandelanotte C. Physical activity recommendations from general practitioners in Australia. Results from a national survey. Aust N Z J Public Health. 2016;40:83-90.

101. Cowan RE. Exercise is medicine initiative: physical activity as a vital sign and prescription in adult rehabilitation practice. Arch Phys Med Rehabil. 2016;97:S232-7.

102. Fortier M, Guerin E, Segar ML. Words matter: reframing exercise medicine for the general population to optimize motivation and create sustainable behaviour change. Appl Phys Nutr Metab. 2016;41:121-1215.

103. Beedie C, Mann S, Jimenez A. Community fitness center-based physical activity interventions: a brief review. Curr Sports Med Rep. 2014;13:267-74.

104. Dean RN, Farrell JM, Kelley ML, Taylor MJ, Rhodes RE. Testing the efficacy of the theory of planned behavior to explain strength training in older adults. J Aging Phys Act. 2006;15:1-12.

105. Winett RA, Davy BM, Savla J, Marinik EL, Kelleher SA, Winett SG, Halliday TM, Williams DM. Theory-based approach for maintaining resistance training in older adults with prediabetes: adherence, barriers, self-regulation strategies, treatment fidelity, costs. TBM. 2015;5:149-59.

106. Williams DM, Dunsiger S, Davy BM, Kelleher SA, Marinik EL, Winett RA. Psychosocial mediators of a theory-based resistance training maintenance intervention for prediabetic adults. Psychol Health. 2016;31:1108-24.

107. Mann S, Jimenez A, Domone S, Beedie C. Comparative effects of three 48week community-based physical activity and exercise interventions on aerobic capacity, total cholesterol and mean arterial blood pressure. BMJ Open Sport Exerc Med. 2016;2:e000105.

\section{Submit your next manuscript to BioMed Central and we will help you at every step:}

- We accept pre-submission inquiries

- Our selector tool helps you to find the most relevant journal

- We provide round the clock customer support

- Convenient online submission

- Thorough peer review

- Inclusion in PubMed and all major indexing services

- Maximum visibility for your research

Submit your manuscript at www.biomedcentral.com/submit
Biomed Central 